\title{
Synchronicity and Alignment of Productivity: The Real Value from Services
}

\section{Science?}

Stuart Maguire $^{a}$, Udechukwu Ojiako ${ }^{b}$ Thanos Papadopoulos $^{b}$, Farhad Shafti ${ }^{c}$, Lenny Koh $^{\mathrm{a}}$, Panagiotis Kanellis ${ }^{\mathrm{d}}$,

${ }^{a}$ University of Sheffield (UK), ${ }^{b}$ University of Southampton (UK) ${ }^{c}$ University of Strathclyde (UK) ${ }^{\text {d }}$ Ernst \& Young (Greece)

The ability of service to pervade all aspects of productivity creates the need for an interdisciplinary framework of service to be developed. It is however critical that any proposed service framework is developed jointly between service purveyor and stakeholders. An expected outcome from a focus on productivity in the Services Science arena is that a much closer relationship between the purveyor of a service and the customer is initiated and fostered. This requires a clear focus on the requirements of the customer and the various ways the service can be conveyed. This is not too far removed from what is required in other areas such as product specification that should also be carefully crafted from the needs of the customer. The research utilises two case studies to highlight the impact of Services Science as a co-producer of service productivity. We find from the case studies that human factors play an extremely important role in improving service productivity.

Keywords: Service Delivery, Productivity, Customers, Synchronicity. 